EVIDENCE BASED PUBLIC HELATH POLICY AND PRACTICE

\title{
Diseases of comfort: primary cause of death in the 22nd century
}

\author{
Bernard C K Choi, David J Hunter, Walter Tsou, Peter Sainsbury
}

J Epidemiol Community Health 2005;59:1030-1034. doi: 10.1136/jech.2005.032805

See end of article for authors' affiliations

....................

Correspondence to:

Dr B Choi, Centre for Chronic Disease

Prevention and Control (CCDPC), Public Health Agency of Canada (PHAC), Government of Canada, AL no 6701A 120 Colonnade Road, Ottawa, Ontario K1A 1B4, Canada; Bernard_Choi@ phac-aspc.gc.ca

Accepted for publication 20 July 2005

$\mathrm{T}$ hree public health questions dominate policy discussion in the opening years of the 21 st century: What is really driving the global chronic disease epidemic? Why are demands on health care rising, putting growing pressure on health care expenditure? What has to happen to stem the rising tide of obesity and physical inactivity? With what is claimed to be human progress playing a part in the answer to them, these central questions may be the tip of the iceberg warning signs that, in this and the 22nd centuries, the human race will be pushed towards a primary cause of death from "diseases of comfort" (such as those chronic diseases caused by obesity and physical inactivity), due to technological advance.

\section{THE ILL}

How does human progress and civilisation play a part in the global chronic disease epidemic? The Whiggish view suggests that human history is a record of continuous progress toward perfection. ${ }^{1}$ Or is it? An alternative reading of history is that the search for perfection and the assumption of "progress" are misplaced. Certain inventions and technological changes neither improve on the present nor represent progress. While we celebrate scientific knowledge alongside economic growth and productivity - the so called "growth fetish"2 —we should be aware of their impact on the poor, on work-life balance, on stress levels in the workforce, and on lifestyles, such as physical inactivity, imbalanced diet, smoking, and excessive alcohol, that could be health damaging (table 1). The modern myth is that science enables humanity to take charge of its collective destiny. But, "in truth there are only humans, using the growing knowledge given them by science to pursue their conflicting ends". ${ }^{3}$

The biggest technological innovation in history is perhaps the invention of electric appliances and powered machineries. ${ }^{45}$ Although they may add to the comfort, convenience, or pleasure of living, they also introduce public health problems. Since the invention of electric lighting, such as the first incandescent lamp (by Thomas Edison in 1879), ${ }^{4}$ the electric motor and generator, and electronic equipment, the quality of life has improved for many people. However, there are unanticipated side effects. The television (TV, invented in 1925), ${ }^{5}$ and more recently the computer and computer games (increasingly popular since 1980), extend the hours of indoor sedentary entertainment. Children are hooked on to television sets and computers for long hours, instead of playing physical games in the backyard or in local playgrounds and parks.

Technology adds to the complex and interrelated social dynamics that are in operation, as the modern sedentary lifestyle is also a result of design issues. Presumably unintentionally, many planners and developers design crime in and safety out of many communities and neighbourhoods. Streets and public areas become unsafe because of the way buildings and spaces are configured. There are also community safety issues arising from perceptions (often misplaced and fuelled by the media) that crime is on the increase and that our streets are unsafe. Increases in traffic volume can lead to the same outcome. This makes parents overprotective of their children with the result that children become housebound rather than encouraged to play on the streets. Confined indoors it is little wonder that they seek diversion in television and computer games, thereby completing the vicious circle.

Invention of the first automobile, or self powered wheeled vehicle (by Thomas Newcomen in 1705), ${ }^{5}$ changed the whole lifestyle of people. Children are now driven to school, instead of walking. Also, clothes washers, dryers, and dish washers take away the opportunities of old fashioned household physical activities. Even sweeping the footpath has been replaced by (environmentally unfriendly) petrol powered blowers. Robots, or servomechanisms (invented in 1921), ${ }^{4}$ are now available to perform activities for people.

Another sign of human "progress" is the development of refined and fast food, such as ready to eat and ready to cook 
Table 1 Causes of diseases of comfort

\begin{tabular}{|c|c|c|}
\hline Level & Mechanism & Events \\
\hline (1) Diseases of comfort & problem & $\begin{array}{l}\text { Global chronic disease epidemic of heart diseases, cancers, } \\
\text { respiratory diseases, mental disorders, diabetes, musculoskeletal } \\
\text { disorders, etc }\end{array}$ \\
\hline (2) Immediate causes & $\uparrow$ & Obesity, high blood pressure, high blood cholesterol, stress \\
\hline (3) Underlying causes & $\uparrow$ & Physical inactivity, imbalanced diet, smoking, excessive alcohol \\
\hline (4) Technological advance & $\uparrow$ & $\begin{array}{l}\text { Electricity, machines, automation, energy dense food, poor urban } \\
\text { planning, modern life, globalised economy }\end{array}$ \\
\hline (5) Civilisation & $\uparrow$ & $\begin{array}{l}\text { Human progress towards "perfection" (comfort, convenience and } \\
\text { pleasure) }\end{array}$ \\
\hline
\end{tabular}

food, to go with the faster rhythm of modern life. These foods are so refined and "energy dense" that their nutrients are readily absorbed, providing calories without nutrition ${ }^{6}$ (table 1). Is this modern change in eating habits good or bad for public health? Does it matter that fewer families sit down together to eat food that has been prepared and cooked in the kitchen? Fast food and drive through restaurants, very popular in North America, not quite so evident in Europe although the UK is something of an exception, now also offer meals in increasingly larger portions. The Mediterranean, Japanese, and other traditional diets are very different, ${ }^{78}$ and represent distinct cultures that remain much in evidence although young people in these societies are under intense pressure from flexible labour markets, faster lifestyles, TV advertising, etc, to adopt similar eating habits to those evident in the USA. The fact that these societies are being threatened by fast food lifestyles surely says something about the penetration into different cultures of a particular vigorous form of marketing and competitive behaviour led by a US model of economy and markets. So, again, the issues are complex, interrelated, and global in nature.

The kind of food that we are being encouraged to consume and the choices available to consumers represent not just individual lifestyle changes but the way our very wants and preferences are shaped by commercial conglomerates with sophisticated means of marketing their products and creating demand for them. This is especially evident among young people who can be targeted directly not only via children's programmes on television but also increasingly through mobile telephones that very young children now possess in growing numbers. Developments like TV and faster and cheaper travel make it possible for such forms of cultural imperialism to be projected and disseminated on a global scale. ${ }^{9}$

In the early days, to get light, people had to walk to collect fuel and use friction to start a fire, which can mean hours of physical activity. Then came the oil lamp and the candle, matches (invented by John Walker in 1827) ${ }^{5}$ and the cigarette lighter, which made life easier. An electric lamp brings light on the flick of a switch, but people still need to walk to the switch. Right now there are devices that allow people to clap their hands to turn a lamp on or off, without the walking. More advanced models are based on infrared remote control, but this still requires pushing a button and there is no reason to assume that we have reached the zenith of domestic illuminatory inactivity. In the future, there may be brain wave detection devices so that people simply lie on their couch, and think "give me light". And the light goes on.

\section{THE PILL}

Comfort (which includes convenience and instant gratification) is hard to resist, and is both a benefit and an inevitable price of living in a modern society. One response to diseases of comfort lies in education and in raising individuals' health literacy (table 2). Through awareness and knowledge transfer activities, people may come to realise that comfort has a dark side. For example, enlightened car users may prefer walking instead of driving between stores that are within the same block in an open air shopping centre. Smart diners may, on their own initiative, learn to enjoy eating salad without salad dressing. Public health's role is to promote appropriate use of modern technology to create a built and social environment that encourages walking, exercise, and nutritious food choices.

Health education has an essential role in raising awareness about healthier lifestyle choices among people. But we have to acknowledge the limits of health education. In the USA, a study of national data has shown that only 3\% of Americans followed all four of the recommended health rules, namely, don't smoke, maintain a normal weight, eat fruit and vegetables, and get some exercise. ${ }^{10}{ }^{11}$ The effect of following these lifestyle changes is greater than anything else medicine has to offer but the challenge for the public, policymakers, and public health practitioners is how to achieve these changes. A considerable investment in public health and social marketing should be undertaken to combat the commercialisation of comfort. Other public policy measures are required, too, to give priority to healthy public policy interventions.

Public funds need to be invested in building an environment that provides the comfort of modern living, but also makes healthier lifestyles a desirable and an easy choice. Some examples-none of them new but lamentably absent, ineffective, or poorly implemented-include: encouraging mass transit as a cheaper alternative to driving; clustering worksite and residential homes near public transportation facilities; making bicycle racks a priority feature at building

Table 2 Prevention and control strategies of diseases of comfort

\begin{tabular}{lll}
\hline Level & Mechanism & Events \\
\hline (A) Diseases of comfort & $\downarrow$ & $\begin{array}{l}\text { Global chronic disease epidemic of heart diseases, cancers, respiratory } \\
\text { diseases, mental disorders, diabetes, musculoskeletal disorders, etc }\end{array}$ \\
(B) Interventions & $\downarrow$ & $\begin{array}{l}\text { Education (health literacy), legislation, participative democracy, } \\
\text { intersectoral action, community involvement, healthy technology, built } \\
\text { environment, recreational choices } \\
\text { Comfort choices are healthy choices for all }\end{array}$ \\
$\begin{array}{l}\text { (C) Continuous } \\
\text { civilisation }\end{array}$ & solution & \\
\hline
\end{tabular}




\section{What this paper adds}

This paper describes reasons for the non-communicable disease epidemic and the need for comprehensive health promotion activities to tackle the problem. It is a policy analysis that aims to draw attention to the fact that despite the available research evidence, there remain issues in public health policy that require a new approach. This centres on the need for a political response in thinking afresh about how we might wish to lead our lives. It would include societal developments that are not solely technology driven simply because the technology exists and it is assumed that this must represent progress and improve lives.

entrances; creating neighbourhood business within walking distances of residential homes; and having green space and parks for people and groups to enjoy. Health marketing strategies, such as prompting, product sample, price reduction and store coupons, may be used in the supermarket to increase consumer purchases of healthier foods. ${ }^{12}$ In other words, there is a need for modern urban planning and health marketing to create an enabling environment to encourage healthier lifestyles.

If education fails or is simply not seen as sufficient or appropriate to the nature or scale of the problem-and the evidence is not encouraging-then the answer may lie in legislative action (table 2). Just as seat belt regulations have saved lives, is there a need for fast or junk food regulations? For example, should all salad dressings be calorie reduced? Should all shopping areas be designed to require comfortable walking from store to store? Instead of, or in addition to, coffee or snack breaks, how about physical exercise breaks at work and school?

Public health needs to promote a balance between education and legislation. Some public health practitioners may not feel philosophically prepared to embrace public health legislation, for example, fast food legislation, unless we have already done everything we can to educate the public. On the other hand, it may not be possible for public health practitioners to do all we can to educate people about food before we support government action to regulate the availability of certain foods or the amount of sugar and salt they contain, because there isn't time given the rapid rise of comfort related and other lifestyle diseases especially among young people. Public health needs to act now to tackle the problem through the support of a combination of education and legislation. For example, it makes no sense to give children messages about healthy eating at school when the vending machines in those same schools are stuffed with junk food snacks and fizzy drinks. Where is the logic in that? Commercial pressures are the reason but both education and legislation are required to regulate such activities so that consistent messages are given to the public. Confronting the powerful vested interests that shape our lives cannot be left to individuals. Only participative, democratic governments, whether national, regional or local, through concerted efforts with other sectors and the community, can be relied on to act on behalf of individuals. For example, it is welcome news that several provinces in Canada have now banned calorie laden junk foods from elementary school vending machines—crackers and milk are in; donuts and soft drinks are out. ${ }^{13} 14$

Health care costs are on the rise because of the modern epidemic of diseases of comfort. Costs are not (yet) spiralling out of control but they may soon be. The Wanless report prepared for the UK Treasury looked at the pressures on health care funding over a 20 year period from 2002 to 2022 ,

\section{Policy implications}

This paper has extensive and global policy implications, as revealed by the peer reviewers' comments: "The paper is timely and can be potentially useful for health policy makers", and "This is an important paper that has potential to affect policy making all over the world". Public health leaders need to become more visible and assertive, and to challenge the assumptions, stated or otherwise, around concepts such as "progress", "modernisation", and "globalisation". Health policies can and should be developed to make sure that the same science and technology that has created comfort choices, in the course of human "progress" and civilisation, must ensure that comfort choices are also healthy choices for all and not merely the few.

and concluded that by 2022 if a grip was not achieved in respect of upstream public health measures then the demand pressures on the NHS would become unsustainable for a publicly funded system of health care..$^{15} \mathrm{New}$ drugs just about to hit the marketplace threaten to distress nationally funded health systems unless we adopt a different approach to our health-the notion of a "pill for every ill" and an "ill for every pill" has to be confronted. ${ }^{17-19}$ People will generally go for the easy quick fix rather than the preventive approach that may require personal sacrifices and lifestyle changes that seem less palatable. But with more than one billion adults worldwide overweight and at least 300 million clinically obese, and a global average of $41 \%$ of adults having insufficient physical activity, ${ }^{20}$ medical treatment of chronic diseases on a case by case basis will soon be out of the question, and mass prevention and control strategies (such as education and legislation) will be key. Public health has now reached a point where we need some more concrete suggestions, even if in fairly general terms, about what people, industries, governments, non-profit organisations and society can and must do to tackle lifestyle diseases that threaten the longevity of current and future generations.

\section{THE THRILL}

There are public health examples of success in changing population behaviours. Smoking is a strong preventable factor that health promotion activities have targeted and obtained some results in some parts of the world. For example, increased tobacco excise taxes and a comprehensive tobacco programme have been shown to be appropriate public health approaches to reduce population smoking prevalence, reducing smoking to $18 \%$ in California. ${ }^{21}{ }^{22}$ Despite a general deterioration of diet, nutrition has provided a few success stories. Population cholesterol levels were found to be reduced by subsidising berry farming in North Karelia, Finland ${ }^{23}{ }^{24}$; and by introducing soybean oil alongside an intensive public health education in Mauritius. ${ }^{25}{ }^{26}$

The same technology developed to bring us comfort, convenience, and pleasure of living can also be designed to bring us healthy living. There is today ample evidence supporting the association between longevity and food intake patterns. The European prospective envestigation into cancer and nutrition (EPIC) study confirmed the association between diet, nutritional status, various lifestyle and environmental factors, and the incidence of different forms of cancer and other chronic diseases. ${ }^{827}$ These and many other studies can be used to design better health promotion and chronic disease prevention and control strategies.

A single daily pill, or a "Polypill", that contains six ingredients-aspirin, a statin, three blood pressure lowering agents, and folic acid-has been proposed for all people over 
55 years regardless of their risk status to target major cardiovascular risk factors, as a more efficient strategy than promoting healthy life style. ${ }^{28}$ The proposal was based on a review of over 750 trials with 400000 participants. ${ }^{29}$ A "Polymeal" that is based on a healthy diet of seven food components-wine, fish, chocolate, fruits, vegetables, garlic, and nuts-has also been recommended as a safer and tastier alternative than the Polypill to reduce cardiovascular disease. ${ }^{30}$ Although critics, including ourselves, may consider the Polypill to be too much like "Polyfilla" (a crack filler) in terms of papering over the visible problem and disguising the root causes, the Polymeal could use modern technology and knowledge to promote public health by changing unhealthy behaviours.

\section{CONCLUSIONS}

The needs of the collective are not the same as the sum of individual preferences. The principal role of stewardship and governance is the protection of the population's health. This is an essential role for government but it must include intersectoral collaboration with the private sector and nongovernment organisations and community involvement in decision making and action. Collective responsibility and action should not be abandoned in favour of a focus on individual choice and consumer models of health promotion and prevention in which it is all a matter of giving people information and advice to allow them to exercise informed choice. The growing marketisation of public policy threatens and weakens the legitimate stewardship role of government as the ties between individuals as citizens and the state become looser to be replaced by individuals acting as consumers in a marketplace. In countries with more developed economies, we take safe water for granted so why not safe food that has reduced levels of fat, sugar, and salt in line with international healthy guidelines? ${ }^{31}$

There is a need for a more vigorous critique of the notion of human "progress", particularly one that is economically driven and adheres to a particular conception of progress and economic development. Public health needs to be more passionate about health issues associated with human progress and adopt a health promotion stance. Its practitioners can no longer merely be dispassionate bystanders. Many people are helpless when faced with largely unhealthy choices. Public health should be leading the way, pointing out that diseases of comfort are an outcome of human "progress" and civilisation, and ensuring that, through health promoting education, built and social environments and legislation, comfort choices are healthy choices for all and not merely the few. For this to happen, the public health workforce needs to be equipped with the necessary skills and critical perspectives to tackle the issues identified in this paper.

We believe our message is a clear one. It may not be new but bears repeating. Public health has to become more assertive and politically aware and a powerful advocate for political and social change. In recent times, public health has failed to display these qualities and attributes. Public health leaders need to become more visible and vocal and to challenge the dogma surrounding concepts like "progress" and "modernisation" when it comes to promoting health. By restating the facts that are known to many, this paper by an international authorship is a call for global action to spread and act on the message-before it is too late.

\section{ACKNOWLEDGEMENTS}

The authors acknowledge the helpful suggestions and support of Dr Christina Mills, past president of the Canadian Public Health Association, and the assistance of Professor Theodore Binnema, associate professor of history, University of Northern British
Colombia, Canada in the interpretation of the Whiggish view of history.

\section{AUTHOR CONTRIBUTIONS}

Study concept and design: Choi. Acquisition of data: Choi, Hunter, Tsou, Sainsbury. Analysis and interpretation of data: Choi, Hunter, Tsou, Sainsbury. Drafting of the manuscript: Choi. Critical revision of the manuscript for important intellectual content: Choi, Hunter, Tsou, Sainsbury. Final approval of the version to be published: Choi, Hunter, Tsou, Sainsbury

\section{Authors' affiliations}

B C K Choi, Public Health Agency of Canada (PHAC); Department of Public Health Sciences, University of Toronto; Department of Epidemiology and Community Medicine, University of Ottawa, Canada D J Hunter, UK Public Health Association (UKPHA); School for Health, Wolfson Research Institute, University of Durham, Durham, UK W Tsou, American Public Health Association (APHA); Tsou Consulting, Philadelphia, Pennsylvania, USA

P Sainsbury, Public Health Association of Australia (PHAA); Division of Population Health, Sydney South West Area Health Service-Eastern zone; School of Public Health, University of Sydney, Camperdown, NSW, Australia

Funding: none.

Conflicts of interest: none declared.

Views expressed are those of the authors and cannot be attributed to any agencies, associations, universities, or organisations.

\section{REFERENCES}

1 Butterfield $\mathbf{H}$. The Whig interpretation of history. London: G Bell and Sons, 1931, Html edition for Eliohs by Guido Abbattista, Feb 2002. http:// www.eliohs.unifi.it/testi/900/butterfield/ (accessed on 21 Oct 2004).

2 Hamilton C. Growth fetish. London: Pluto Press, 2004.

3 Gray J. Al Qaeda and what it means to be modern. London: Farber and Farber, 2003.

4 The new college encyclopedia. New York: Galahad Books, 1978.

5 Funk and Wagnalls new encyclopedia. Oxford: Oxford University Press, 1993.

6 Prentice AM, Jebb SA. Fast foods, energy density and obesity: a possible mechanistic link. Obesity Reviews 2003;4:187-94.

7 Esposito K, Marfella R, Ciotola M, et al. Effect of a Mediterranean-style diet on endothelial dysfunction and markers of vascular inflammation in the metabolic syndrome: a randomized trial. JAMA 2004;292:1440-6.

8 Trichopoulou A. Modified Mediterranean diet and survival: EPIC-elderly prospective cohort study. BMJ 2005;330:991-5.

9 Choi BCK, Bonita R, McQueen DV. The need for global risk factor surveillance. $J$ Epidemiol Community Health 2001;55:370.

10 Reeves MJ, Rafferty AP. Healthy lifestyle characteristics among adults in the United States, 2000. Arch Intern Med 2005;165:854-7.

11 Hopkins Tanne J. Only 3\% of US citizens follow good health advice. BMJ 2005;330:1044.

12 Paine-Andrews A, Francisco VT, Fawcett SB, et al. Health marketing in the supermarket: using prompting, product sampling, and price reduction to increase customer purchases of lower-fat items. Health Mark Q 1996; 14:85-99.

13 Boyle T. Kennedy spelling out what's in and out as junk food in schools. Toronto Star 2004; 20 Oct:A24.

14 CBC News. Sell milk, not pop, Ontario tells schools. http://www.cbc.ca/ story/canada/national/2004/10/20/ont_food_schools041020.htm (accessed on 21 Oct 2004).

15 Wanless D. Securing our future health: taking a long-term view. Final report. London: HM Treasury, 2002.

16 Moore W. Wanless report outlines "Rolls-Royce" health service for 2022. BMJ 2002;324:998.

17 Lam CL, Catarivas MG, Lauder IJ. A pill for every ill? Fam Pract 1995; 12:171-5.

18 Swan L. A pill for every ill. Circulation 2002; 105:e82.

19 Cotter A. An ill for every pill? Nurs Times 1983;79:12-14.

20 WHO. The world health report 2002. Geneva: World Health Organisation, 2002.

21 Pierce JP, Gilpin EA, Emery SL, et al. Has the California tobacco control program reduced smoking? JAMA 1998;280:893-9.

22 California Department of Health Services. Adult smoking prevalence. http:// www.dhs.ca.gov/tobacco/documents/AdultSmoking.pdf (accessed on 3 Jun 2005).

23 Pekka P, Pirjo P, Ulla U. Influencing public nutrition for noncommunicable disease prevention: from community intervention to national programme-experiences from Finland. Public Health Nutrition 2002;5:245-51. 
24 Kuusipalo J, Mikkola M Moisio S, et al. The East Finland berry and vegetable project: a health-related structural intervention programme. Health Promotion 1986;1:385-91

25 Uusitalo U, Feskens EJ, Tuomilehto J, et al. Fall in total cholesterol concentration over five years in association with changes in fatty acid composition of cooking oil in Mauritius: cross sectional survey. BMJ 1996;313:1044-6

26 Goburdhum D, Jhaumeer-Laullo SB, Musruck R. Evaluation of soybean oil quality during conventional frying by FTIR and some chemical indexes. Int J Food Sci Nutr 2001:52:31-42.

27 Slimani N, Southgate D, Van Staveren W, et al. Food consumption, anthropometrics and physical activity in the EPIC cohorts from 10 European countries: food consumption data derived from the calibration study. Public Health Nutrition 2002;5(suppl): $1111-345$

28 Wald NJ, Law MR. A strategy to reduce cardiovascular disease by more than 80\%. BMJ 2003;326:1419-23.

29 Rodgers A. A cure for cardiovascular disease? BMJ 2003;326:1407-8.

30 Franco $\mathrm{OH}$, Bonneux L, de Laet $\mathrm{C}$, et al. The Polymeal: a more natural, safer, and probably tastier (than the Polypill) strategy to reduce cardiovascular disease by more than 75\%. BMJ 2004;329:1447-50.

31 WHO. Global strategy on diet, physical activity and health Fifty-Seventh World Health Assembly, 22 May 2004. (WHA57.17. ) http:// www.who.int/gb/ebwha/pdf_files/WHA57/A57_R17-en.pdf (accessed on 22 Oct 2004).

\section{THE JECH GALLERY}

\section{From steam engines to Sunny Delight}

$\mathrm{T}$ he St Rollox works in Springburn (top left image-in 1955) was the last surviving locomotive works in Scotland. At the height of production during the first world war the St Rollox complex covered over 190 acres and provided work for about 5000 men. In 1965 the works underwent major renovations at a cost of $£ 1.5$ million (top right). By the early 1980s however the works had failed to make the transition from steam technology to modern diesel and electric engines. As a result thousands of jobs were lost when the works closed. In 1987 the site was described as a scene of "urban desolation" with poor quality high rise housing (middle left) and the area suffered from severe decline (middle right). Policymakers have suggested that the development of food superstores in deprived communities can improve the diet and health of residents, and stimulate the local economy. ${ }^{1}$ As part of a public-private initiative the site of the St Rollox works was re-developed by the Tesco St Rollox Partnership at a cost of about $£ 25$ million (bottom left)—sacrificing some green space for a tarmac car park and associated transport infrastructure. The hypermarket, which opened in November 2001, promised jobs and training to the local unemployed. ${ }^{2} \mathrm{~A}$ recent evaluation of this initiative suggested only limited impacts on health and little impact on fruit and vegetable consumption. ${ }^{3}$ Opening supermarkets in deprived communities may not be the single most effective approach to improve local diets. Commercial reality is such that all supermarkets provide opportunities to consume both healthy and unhealthy products. The image (bottom right) illustrates this point: the large tins of confectionary and the Sunny Delight fruit drinks in this prominent display both contain high levels of sugar and are particularly attractive to children.

\section{ACKNOWLEDGEMENTS}

Digital images (photos 1-4) used in this article are from the Springburn Virtual Museum, part of the Glasgow Digital Library. For more information please go to http://gdl.cdlr.strath.ac.uk/springburn/ and http://gdl.cdlr.strath.ac.uk/. The authors prepared this paper while funded by a grant from the Department of Health Reducing Health Inequalities Initiative (ref 121/7492). The views expressed here are those of the authors and not necessarily those of the Department of Health.

S C J Cummins Department of Geography, Queen Mary, University of London, London, UK
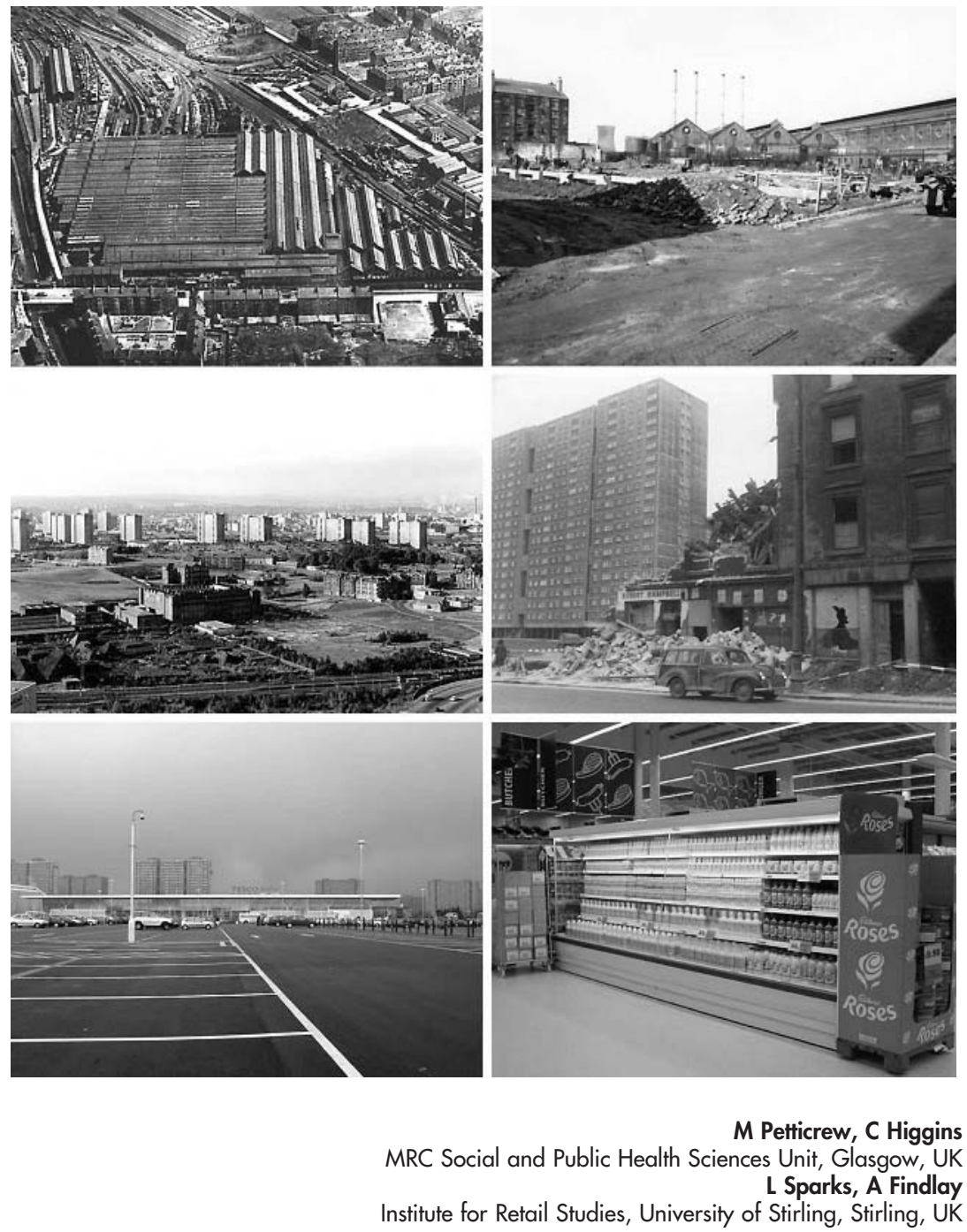

Correspondence to: Dr S C J Cummins, Queen Mary, University of London, Mile End Road, London E1 4NS, UK; s.c.j.cummins@qmul.ac.uk

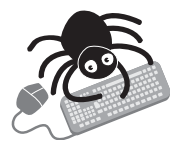
Colour versions of the images are available on line (http://www.jech.com/ supplemental).

\section{REFERENCES}

1 Department of Health. Policy Action Team 13: Improving shopping access for people living in deprived neighbourhoods. London: Department of Health, 1999.

2 Tesco Stores Limited. St Rollox Partnership [Evaluation Report]. Dundee: Tesco Stores Limited, 2002.

3 Cummins S, Petticrew M, Higgins C, et al. Large scale food retailing as an intervention for diet and health: quasi-experimental evaluation of a natural experiment. J Epidemiol Community Health 2005;59:1035-40. 